\title{
Memória e História: Hannah Arendt em diálogo com Walter Benjamin
}

\author{
MARIONILDE BREPOHL DE MAGALHÃES*
}

\begin{abstract}
Resumo: A autora tem como proposta refletir sobre o papel da memória e da História em nossa cultura contemporânea, através de uma aproximação ao pensamento de Hannah Arendt e Walter Benjamin.
\end{abstract}

Abstract: The author has as purpose to reflect about the role of memory and History in our contemporary culture, through an approximation to the thought of Hannah Arendt and Walter Benjamin.

Palavras-chave: História. Memória. Hannah Arendt. Walter Benjamin.

Key words: History. Memory. Hannah Arendt. Walter Benjamin.

O fogo do amor pode queimar de longe, mas nada pode iluminar a noite ..., essa parece ser a epígrafe do filme Muito além do fim do mundo, de Wim Wenders, produzido com Peter Handke, em 1991.1

O tema central da película consiste na fabricação de imagens digitalizadas, por meio de alta tecnologia, para que uma mulher, cega desde os oito anos de idade, possa enxergar, conformando com isso uma memória artificial de seus entes queridos, bem como passagens de sua vida que não puderam ser inteiramente vivenciadas.

Wim Wenders inicia o filme narrando ao espectador que no ano de 1999, portanto, num futuro não muito distante, um satélite indiano teria se desviado de sua rota, rumando descontrolado até a camada de ozônio da terra, o que teria causado pânico em todos os habitantes do planeta, pois as conseqüências eram imprevisíveis. No entanto, afirma o narrador, a jovem Claire Tournieur (personagem interpretada por Solveig Dommartin) parecia pouco se importar com os riscos iminentes derivados daqueles acontecimentos, porquanto ela tinha os seus próprios pesadelos. Sonhava estar em um outro lugar que não o seu, o que, no começo, era muito agradável, mas, depois, causava-lhe pânico.

* Universidade Federal do Paraná.

1 Roadmovies - Filmproduktion Berlin - Argos Films Paris.

Estudos Ibero-Americanos. PUCRS, Edição Especial, n. 2, p. 49-60, 2006 
Claire, que usa uma peruca retrô, ao estilo de Louise Brooks, e roupas em estilo dark, é o protótipo de uma pessoa desenraizada, e parece querer se lançar no mundo, aventurar-se a algo que vá mais além do que suas próprias sensações.

Numa dessas noites, acordou num lugar estranho, e resolveu ir para Paris. No princípio, conduziu seu carro na estrada recomendada no computador que orientava sua rota; pouco depois, sem quaisquer explicações, Claire tomou uma outra estrada, não mapeada pelo softer que trazia consigo. Neste caminho, sofre uma colisão com outro carro, dirigido por assaltantes de um banco que acabam propondo a ela que levasse a mala de dinheiro até Paris, em troca de $30 \%$ do montante roubado. Claire aceita a tarefa e, em lá chegando, encontra-se, por acaso, com Trevor McPhee (William Hurt). Ele está sendo perseguido por razões que não são reveladas, o que Claire percebe com clara nitidez. Em virtude de seu enamoramento pelo suspeito, Claire abandona seu namorado David (David Gulpilil, que é também o eu-narrador do filme), para aventurar-se a diversas viagens com o novo amante, como para Lisboa, Berlim, Moscou, Bejing e Tóquio. Após diversas peripécias para escapar dos algozes, Trevor revela a Claire sua verdadeira identidade: seu nome é Sam Forber, filho de um importante cientista, Henry Forber (Max von Sidow), que desenvolveu seus estudos nos Estados Unidos e que, após anos de pesquisa na área de oftalmologia, descobriu uma tecnologia biônica, pela qual, um computador podia enviar impulsos eletromecânicos pelas fibras nervosas do cérebro, recriando o ato bioquímico de ver.

A câmera que McPhee/Forber carregava consigo gravava imagens que poderiam depois ser transmitidas à sua mãe, Edith Forber (Jeanne Moreau), desde que passassem por um outro cérebro humano. Bastava revê-las em uma grande tela de computador, e as vibrações dos neurônios da pessoa sã seriam reenviadas ao córtex cerebral da mulher cega, ela também, conectada a um terminal de computador. E era precisamente essa máquina que seus perseguidores queriam, agentes de espionagem industrial norte-americana, interessados em usar tal máquina para os serviços de inteligência de seu país.

Comovida com as intenções de Sam, e já sem a peruca, mostrando seus cabelos loiros e crespos, Claire o acompanha na viagem até o local em que reside sua mãe (muito possivelmente, no interior da Austrália). 
Entrementes, uma explosão nuclear, provocada pelos Estados Unidos para detonar o satélite indiano, leva ao apagamento da memória de todos os computadores do planeta. $\mathrm{O}$ eu-narrador declara esse evento levaria ao fim do mundo.

Mesmo com todas as dificuldades enfrentadas pela ausência de tecnologia, o casal consegue chegar ao lugar de destino, para onde também fora o ex-namorado de Claire, David. Era um país abandonado há anos, em virtude de uma estiagem prolongada. Ali, além do casal Forber e seus assistentes técnicos, só residia o povo nativo, denominado mbantua, num estágio tecnológico e social muito aquém do seu tempo.

O experimento é realizado com as fotografias e vídeos produzidos por Sam, que, no entanto, não consegue retransmiti-los à mãe, pois além de olhá-los, era necessário retê-los na memória por alguns instantes, o que Sam não conseguia fazer. Logo é Claire que passa a desempenhar, com sucesso, tal façanha, e Edith consegue "ver": sua filha, sua neta, seu cunhado, todos e tudo que, conquanto em um tempo cuja efemeridade fosse inevitável, a nova técnica lhe permitia.

Aos espectadores, o narrador informa que a experiência teria sido uma decepção para Edith, fato que ela não revela aos seus familiares para não decepcioná-los: no fundo, preferia a época em que não podia ver nada, pois ali, naquela escuridão, estava mais próxima de seu eu interior. Se foi pela experiência ou se foi por alguma outra doença, não se pode saber, mas o fato é que às vésperas do ano 2000 ela morre, tranqüila e segura, deixando o marido aparentemente inconsolável.

Ocorre a ele, a partir daí, prosseguir com o desenvolvimento da pesquisa, pois se a máquina podia reproduzir imagens de um cérebro, por que não desvendar os mistérios da alma humana? Seu primeiro alvo é o próprio povo Mbantua, que, no entanto, se recusa a desvelar seu eu-interior ao oftalmologista; um dos membros da comunidade afirma que o seu povo não estava disposto a revelar-lhe seus segredos; abandona em seguida Henry, rompendo com uma relação amistosa de muitos anos. O segundo alvo, Claire e Sam, aceitam participar do experimento e são observados por David, que acompanha e registra os efeitos daquela interação entre homem e máquina e de seus efeitos sobre as mentes do casal de amantes.

Principalmente Claire, mas não somente ela, viciou-se na "máquina de produzir memória". Passa o dia olhando, na tela de um micro-computador, o seu próprio passado, os seus desejos mais recônditos, dela mesma ocultados ou interditos. Desfaz os vínculos com as pessoas que a rodeiam, até mesmo com Sam. Importa-lhe apenas espiar e indagar seu passado adormecido, como uma "voyeur" de si mesma. 
Para salvá-la e trazê-la à "normalidade" de sua vida cotidiana, David a conduz de volta para casa e a impede de continuar a utilizar o pequeno computador com que podia ver as imagens de si. Doravante, Claire se transformaria em uma astronauta, o que de certa forma levou à concretização de seu sonho original, o de estar em um lugar distante. Quanto a Sam, fica morando naquela região entre os nativos, perdido no labirinto de sua própria alma. E David escreve um romance sobre tal aventura, o que se transforma em narrativa da ficção.

Em síntese, esse é o roteiro do filme. O que permeia toda a trama e seus personagens é o risco de se perder o passado, ao perder-se a memória ou simplesmente não possuí-la. A ameaça nuclear apagou toda a memória artificial registrada em computadores, e poderia ainda arrasar a vida do planeta, portanto, com o mundo humano. Um outro risco: devido ao contato intermitente com os meios de comunicação, incluindo aí a mídia interativa, bloqueavase o tempo das lembranças.

Ademais, não é apenas Edith, a mulher cega, que encontra dificuldades de guardar suas lembranças - ela deixou de enxergar, e isso é muito sugestivo no plano simbólico -, no mesmo período em que o nacional-socialismo ascendia na Alemanha, de onde vieram tanto ela quanto o marido. Também o filho não consegue guardar, sequer por um bocadinho de tempo, as imagens que acabava de ver na grande tela. Quanto a Claire, cuja origem não é mencionada, ao lograr êxito na tarefa de transmitir as imagens - acaba se viciando - o termo empregado é precisamente este - na visualização de seus próprios sonhos. É através deles que ela vem a conhecer sua própria infância, tanto quanto imagens prazerosas de sua vida pregressa. E mesmo o cientista não suporta lembrar, pois após a morte da mulher, para defender-se do processo de luto em relação à esposa - a lembrança da perda - dedica-se à continuidade de suas pesquisas, e depois retorna aos Estados Unidos.

$\mathrm{O}$ enredo se desenvolve num cenário de ficção científica, em que imagens plásticas se sucedem uma a outra, permeadas por indivíduos que interagem permanentemente com máquinas. A velocidade das imagens virtuais, próprias dos computadores "inteligentes", que atuam semelhantemente à tele-tela de Orwell, no livro $1984^{2}$, parecem se transformar em sistemas cibernéticos de governo do cotidiano. Essa técnica multiplica e amplia enormemente o regime de visibilidade, como que concretizando a utopia

2 ORWELL, G. 1984. São Paulo: Nacional, 1984. 
panótica de Jeremy Bentham; tudo é eletronicamente vigiado e todos são simultaneamente vigias. ${ }^{3}$

No final do filme, a natureza quase intacta da região dos Mbantua, representando, talvez, o começo e o fim do mundo. Mas até mesmo ali, dentro de uma caverna, impera o poder da civilização da técnica, representado pelo laboratório secreto de Henry Forbes.

Finalmente, uma nave espacial, a partir de onde Claire espia o mundo, estando a serviço da paz norte-americana.

\section{Entre a memória e a História}

Esse filme nos inspirou a refletir sobre o papel da memória e da História em nossa cultura contemporânea, aproximando-nos das reflexões de Hannah Arendt. No seu ensaio O conceito de História antigo e moderno ${ }^{4}$ Arendt não disfarça sua preferência pelo conceito clássico de História, ele mesmo um evento apresentado como de notável importância.

Em outro texto, intitulado Walter Benjamin, 5 deixa mais explícito uma outra fonte de inspiração para suas reflexões sobre a história: o conceito de História formulado por Walter Benjamin, ${ }^{6}$ que se traduz pela noção de "modelo exemplar". Como Benjamin, Arendt entende que o passado enquanto tradição oculta, pode iluminar o presente, valendo-se como exemplo da palavra política, uma invenção ateniense do século $\mathrm{V}$ a. $\mathrm{C}$, e que chega até os nossos dias como uma tradição que incita ao debate e à liberdade no pensar e no agir. Assim, propõe a metáfora de que determinadas experiências históricas podem ser representadas como pérolas que estão no fundo do mar aguardando o pescador para trazê-las à superfície.7 O historia-

3 Em outro filme de Wim Wenders, O fim da violência (1997, produzido com Nikolas Klein), a existência de um panótico não edificado espacialmente, mas virtual, é-nos mais uma vez apresentado como um regime de visibilidade total, o que também se aproxima da utopia de Bentham. Sobre Bentham, ver: FOUCAULT, M. Vigiar e punir. Petrópolis: Vozes, 1986, p. 20 e segs.

4 ARENDT, Hannah. O conceito de História - antigo e moderno. In: ARENDT, Hannah. Entre o passado e o futuro. São Paulo: Perspectiva, 1972, p. 43-126.

5 ARENDT, Hannah. Walter Benjamin. In: ARENDT, Hannah. Homens em tempos sombrios. São Paulo: Companhia das Letras, 1987, p. 133-176.

6 Entre outros textos, ver: Sobre o conceito de História. In: BENJAMIN, Walter. Obras escolhidas: magia e técnica, arte e política. São Paulo: Brasiliense, 1985, p. 222 e segs.

7 ARENDT, Homens..., op. cit., p. 176. Neste mesmo texto, ela menciona que mesmo no mundo moderno, em que o passado é recorrentemente questionado, ao menos na linguagem, ele está contido de forma indelével, em nossas experiências, citando como exemplo, que A polis grega continuará a estar presente no fundo de nossa existência política, no fundo do mar, enquanto utilizarmos a palavra política (p. 304). 
dor poderia ser então comparado ao pescador de pérolas, indo à profundidade da experiência humana, e não para trás, como no tempo cronológico.

Essa noção, tanto em Arendt quanto em Benjamin, é tributária do conceito de tempo messiânico judaico-cristão, ou o kairòs, o que nos faz entender o elogio da autora à Revolução, momento de ruptura radical que funda o novo, ao abrigo da plena liberdade. ${ }^{8}$

Seja no texto Walter Benjamin, seja no texto O conceito de história: antigo e moderno, as metáforas e citações empregadas por Arendt nos apontam para uma discordância fundamental em relação à historiografia tal qual ela era praticada em seu tempo: primeiro, a recusa à noção de tempo linear, como faziam os positivistas e historicistas, e a identificação do passado como um tempo que é evocado ou assalta o tempo presente, precisamente num momento de perigo. ${ }^{9}$ São fragmentos, não continuidades; são rupturas, e não causalidades. É exemplar, e não experiência gasta. São imagens que emergem e submergem, mas não desaparecem para sempre, como Bergson ilustrou a partir da figura de um cone, com o objetivo de evidenciar que a memória é coextensiva à consciência. ${ }^{10}$ Segundo, um profundo pessimismo com respeito à transformação da História em avanço das forças produtivas ou de progresso, pois com isto se reduziria o homem à categoria de peça de engrenagem de uma máquina infernal, movida pela lógica da fabricação, e não da ação.

Explicitemos, com maior vagar, seu entendimento: Em O conceito de história - antigo e moderno, a autora inicia suas reflexões, considerando que na Antigüidade Clássica, História e Memória não eram atividades divisíveis. Mnemosine, a mãe das musas, detinha o saber do passado, e por isso, podia prever o futuro. Era um testemunho, uma forma de conhecimento, e não a memória afetiva que todos nós, modernos, procuramos guardar com respeito a fatos ordinários, por vezes extremamente singelos, mas que evocam nossos desejos e nossas saudades. Citemos como, exemplo, as lembranças dos amantes, cujo tempo do encontro é sacralizado com palavras poéticas que buscam, incessantemente, re-atualizar o ato vivido - a imaginação é a memória que enlouqueceu, ensina-nos o poeto moderno Mario Quintana.

Entre os gregos antigos, todavia, a memória é um meio de conhecimento - e não a lembrança voluntária ou involuntária daquilo que nos causou prazer ou medo, este tempo passado que se presenti-

8 ARENDT, Hannah. Da revolução. São Paulo: Ática, 1998.

9 Sobre o assalto do ou recorrência ao passado no momento de perigo, ver: ARENDT, Entre o passado..., op. cit., p. 33 e seg.

10 BERGSON, Henri. Matéria e memória. São Paulo: Martins Fontes, 1990, p. 125 e seg. 
fica em nossas recordações voluntárias ou inusitadas ou por meio da psicanálise. Para os gregos, a História como memória deveria salvar os feitos humanos do esquecimento, assegurar-lhes evocação pela posteridade, fazendo assim sua própria glória brilhar através dos séculos. ${ }^{11}$

Segundo Arendt, essa atividade do pensamento, cujas linhas divisórias também com a poesia eram, no princípio, pouco definidas, derivava da percepção de que todas as coisas da natureza eram dotadas de perenidade - exceto os homens em sua individualidade. Por essa razão, o imperativo de estender com a fama a curta vida, para citar um verso de Camões, ao elogiar Henrique, o conquistador dos mouros, ele mesmo, Camões, poeta que se queria inspirado no imortal canto e voz divina ${ }^{12}$, abrandava a dor pela condição humana de finitude. A mortalidade significava, então, para os gregos, moverse ao longo de uma linha retilínea em um universo onde tudo, se é que se move, se move em ordem cíclica. ${ }^{13}$ A vida presente, e não a vida após a morte, como entre os cristãos, era a preocupação primeira que norteava a mentalidade grega.

[...] da origem do mundo, de sua composição, de sua ordem dos fenômenos meteorológicos, propõem explicações livres de toda a imaginária dramáticas da teogonia e cosmogonias antigas [...] os homens, a divindade, o mundo formam um universo unificado, homogêneo, todo ele no mesmo plano: são as partes e os aspectos de uma só e mesma physis que põe em jogo, por toda a parte, as mesmas forças, manifesta a mesma potência de vida. ${ }^{14}$

O tema da História entre os gregos é portanto o extraordinário - que provoca um rasgo, uma interrupção na monótona e repetitiva vida biológica, própria do ritmo cíclico da natureza. E o extraordinário só podia ser realizado pela ação humana, termo que na língua grega deriva da palavra nascimento ou fundação.

Mas como dotar, senão pela recordação, os feitos e palavras de alguma permanência? Por certo, nem todos os feitos e palavras seriam recordados, apenas aqueles que merecessem louvor, do qual provinha a glória e a fama de seus autores. Estes homens, ao terem registrada sua ação como memorável, seriam imortalizados, mesmo que seus corpos perecessem.

11 Idem, p. 70

12 CAMÓES, L. Os Lusíadas. Belo Horizonte, s/d; respectivamente, p. 127 e 111. Citado também por Celso Lafer no prefácio do livro Entre o passado e o futuro, op. cit., p. 14.

13 ARENDT, op. cit., p. 71.

14 VERNANT, Jean Pierre. As origens do pensamento grego. São Paulo: DIFEL, 1984, p. 73. 
Já no moderno conceito de História, elaborado a partir dos séculos XVI e XVII, e que coincide com a ascensão das Ciências Naturais, e com ela, a crença de que somente a experimentação seria o aval para a confirmação da verdade, ${ }^{15}$ abandona-se a diferenciação entre o mundo humano e o da natureza. Isso porque, principalmente a partir do século XX, os homens conseguem interferir na natureza a ponto de modificá-la - como é o caso das experiências nucleares, da biomecânica, da robótica, da neuroprótese, 16 para citar alguns exemplos mais atuais e extremos, e que estão presentes no filme de Wim Wenders.

Resulta daí, conforme Arendt, que a própria História foi associada ao progresso técnico, quer pelas correntes positivistas, quer pelas correntes marxistas. Assim procedendo, os interessados em História desqualificam o passado, entendendo-o como processo a ser superado, e se servem da História para prever o futuro. E desqualificam também o sujeito da ação, uma atividade política por excelência, creditando à tecnologia o principal móbil para o avanço das sociedades. Com isso, a ação (por natureza imprevisível e indeterminada) cede lugar, na maioria das análises, ao comportamento, cuja previsibilidade e controle são inclusive celebrados pelos cientistas políticos funcionalistas ou pelos psicólogos behavioristas. Isso sem contar com os procedimentos metodológicos e técnicos da História Demográfica, da História Econômica, e mesmo de uma História política que se deixa orientar por métodos demoscópicos. Refirome também a estudos sobre o cotidiano e a vida privada, que chegam ao elogio do homem sem ação, como um indivíduo que recusa a ou escapa da interferência dos poderes oficiais, numa clara confusão do público com o estatal. Refiro-me aqui, para citar apenas dois exemplos, à coleção História da Vida Privada, em que se menciona a valoração do privado, do íntimo, como um abrigo à intervenção do poder público, este entendido como poder necessariamente repressivo, e não como resultado de consensos possíveis. ${ }^{17}$ Cite-se também a História do cotidiano, criticada por André Burguière, ao afirmar que o grande risco dos procedimentos metodológicos de estudos que buscam conceder cidadania aos humildes, de estudar o habitual por oposição ao excepcional, é o de descambar para uma história populista, celebrando a contribuição de um obscuro camponês que melhora a técnica do essartage, ... (como um) um movimento tão importante quanto o de

15 Idem, p. 86

16 Sobre essas novas atividades da ciência, ver: CARDOSO, Silvia H. A interação homemmáquina. In: <www.cerebromente.org.br/n. 03.editori 3.htm> de 14 de julho de 2005.

17 ARIÈS, P. e DUBY, G. (orgs.). História da Vida Privada. São Paulo: Companhia das Letras, 1990, v. 1, p. 10. 
um general que vence uma guerra. ${ }^{18}$ Sem querer propor aqui uma história elitista, e mesmo reconhecendo o valor estratégico das análises sobre as camadas subalternas, questiono, no entanto, a valoração da quietude (como se fosse, per se, resistência aos "poderosos", numa fácil generalização) em detrimento das atitudes de rebeldia, levando, com isto, à condenação da política como lugar da dominação.

Tal tendência levará também à celebração da Memória, exatamente no momento em que esta se torna cada vez mais curta e ou vinculada exclusivamente aos nossos afetos. Isto porque, a velocidade e multiplicação de informações ao nosso dispor, o bombardeio de imagens e sons sobre os nossos órgãos sensoriais, o tempo que despendemos com a indústria cultural, provocam um verdadeiro bloqueio sobre o ato de lembrar. Não por acaso, segundo Jacy Seixas, arquivos gigantescos, construção de memoriais, coleta de depoimentos se multiplicam em escala geométrica num esforço obsessivo de reconstrução das subjetividades; ${ }^{19}$ não mais os fatos extraordinários e os grandes feitos, pelo contrário, os homens sem fama, alvo do poder de outrem, em suas identidades as mais peculiares, aquelas que orientaram seus projetos de vida pela necessidade, e não pela liberdade, como faziam os gregos antigos, segundo a leitura de Arendt. 20

A memória celebrada aí é, portanto, a memória dos sentimentos, transformada em História, em substituição, senão condenação à racionalização do passado. A memória torna-se um dever, e não uma atividade espontânea, justamente porque o ócio, que permitia a lembrança nas sociedades tradicionais, praticamente desapareceu. Aos historiadores pós-modernos, importa menos a análise, e mais a produção de efeitos sobre o seu público leitor, e isso tem como objetivo a pretensão de que ele se identifique afetivamente com o narrado, tomando partido em favor de suas demandas materiais e existenciais. Assim compreendo uma parcela significativa do estudo sobre as mulheres, os homossexuais, as minorias étnicas, aqueles que, enfim, são enunciados como os "excluídos da

18 BURGUIÈRE, André. A antropologia histórica. In: LE GOFF, Jacques (org.). A história nova. São Paulo: Martins Fontes, 1993, p. 130.

19 SEIXAS, Jacy. Comemorar entre memória e esquecimento: reflexões sobre a memória histórica. História: questões e debates. Curitiba, n. 32, jan./jun. 2000, p. 76.

20 Sobre o elogio à polis, ver: ARENDT, H. A condição humana. Rio de Janeiro: ForenseUniversitária, 1983. Como historiadores, temos consciência de que a importância da esfera do labor e do trabalho, ou seja, a esfera da necessidade, foi muito maior do que as conclusões de Arendt nos fazem supor. No entanto, o primado do econômico sobre o político não se fez presente entre os gregos, e cremos que ela releva, em parte, o estudo da ordenação da vida material no mundo antigo por pretender enfatizar um novo acontecimento: a invenção da política como alternativa à violência. 
história" - não teriam eles qualquer responsabilidade por tal infortúnio?

Segundo esta visão, memória e História se opõem, numa relação de conflito que Jacy Seixas explica nos seguintes termos:

Ao debruçar-se sobre a memória, a historiografia contemporânea pouco tem recorrido às reflexões da filosofia ou da literatura, mas tem estabelecido com a sociologia seu diálogo preferencial. De fato, é a sociologia da memória de Maurice Halbwachs que se constitui na base teórica fundamental à maioria dos trabalhos historiográficos. Neste sentido, é importante assinalar a influência de Halbwachs - que elabora, em 1925, uma sociologia da memória coletiva - sobre Pierre Nora, que no terreno historiográfico elaborará a divisão e oposição entre memória e História. Escreve Nora, em 1984, de forma provocativa: Memória, história: longe de serem sinônimas, tomamos consciência de que tudo as opõe. Nora retoma e se apropria das idéias básicas de Halbwachs - a oposição que estabelece entre memória individual e memória coletiva e, sobretudo, entre memória coletiva e história. À memória coletiva, Halbwachs confere o atributo de atividade natural, espontânea, desinteressada e seletiva, que guarda do passado apenas o que lhe possa ser útil para criar um elo entre o presente e o passado, ao contrário da história que constitui um processo interessado, político, e, portanto, manipulador. ${ }^{21}$

A memória se torna, então, quase que um lenitivo contra a História, como se quem produzisse a História fosse necessária e inextricavelmente articulado aos detentores do poder, e quem produzisse a memória, necessariamente, o portador do "verdadeiro" passado.

Feitas estas considerações, retornemos a Arendt. Parece-nos claro que a autora não ignora a importância da tecnologia no fazer da história no mundo contemporâneo, tampouco ignora as armadilhas das histórias oficiais, que não raramente são transformadas em instrumentos de propaganda da política. Seu estudo não é uma denegação romântica do mundo urbano-industrial em favor de um retorno idílico ao mundo tradicional. Trata-se, segundo nosso entendimento, de colocar em relevo o acontecimento e de trazer à luz o(s) sujeito(s) da ação, notadamente, aqueles que não sucumbiram ao peso das estruturas (cadeias) de causalidade.

21 SEIXAS, Jacy. Percursos de memórias em terras de história: problemáticas atuais. In: BRESCIANI, S.; NAXARA, M. Memória e ressentimento; indagações sobre uma questão sensível. Campinas: Editora da UNICAMP, 2004, p. 40. 
Segundo Benhabib, o que está em causa, para Arendt, é estabelecer uma política de memória e a moralização da historiografia. ${ }^{22}$ Salvar um acontecimento e afirmá-lo como documento/monumento, no sentido em que este termo - monumento - pode ser interpretado no idioma alemão - Denkmal - pense mais uma vez. Significa, a um só tempo, iluminar o presente obscurecido por nossas perplexidades e testemunhar sobre um fato que pode contribuir para transformar o mundo em algo melhor.

Isso não significa uma posição neutra e desprovida de engajamento político por parte do historiador, ou seja, uma posição idealizada deste profissional como produtor de verdades. A este propósito, Benhabib nos chama a atenção para o fato de que para Arendt, ao historiador se impõe um julgamento dos fatos narrados, o que ele faz no momento mesmo da narrativa, julgamento que se diferencia tanto do julgamento moral quanto do jurídico, atitude que lhe permite escapar dos dilemas entre objetivismo e relativismo cultural. ${ }^{23}$ Trata-se de imaginar-se no lugar do narrado, apresentando o caráter plural dos homens em suas múltiplas cosmovisões, como a própria Arendt o fez, por exemplo, ao dissertar sobre a mentalidade dos anti-semitas europeus na passagem do século XIX para o XX e a mentalidade dos Boeurs, na África do Sul. ${ }^{24}$

Segundo minha compreensão sobre tal entendimento, trata-se de depor como uma testemunha, e não de ditar sentenças, como um juiz. $\mathrm{O}$ historiador prestaria, com seu trabalho, um testemunho sobre aquilo que ele ouviu e viu, não a partir de uma experiência vivida (como na figura d'O narrador, de Walter Benjamin'25), mas através dos documentos que incitam sua imaginação e que o leva a perguntar, como uma criança de sete anos na idade dos porquês - aquilo que efetivamente aconteceu, porque foi assim e não de outra maneira, para distinguir, enfim, o certo do errado, o belo do feio. ${ }^{26}$ Segundo Arendt, isso pode impedir catástrofes, ao menos para mim mesmo. 27

22 BENHABIB, Seyla. The reluctant modernism of Hannah Arendt. London: Sage Publications, 1996, p. 86 e segs.

23 Idem, p. 89.

24 ARENDT, H. O sistema totalitário. Lisboa: D. Quixote, 1978. Respectivamente: p. 45 e segs., p. 253 e seg.

25 BENJAMIN, Walter. O narrador. Considerações sobre a obra de Nikolai Leskow. In: BENJAMIN, op. cit., p. 197 e segs.

26 ARENDT, Hannah. Pensamentos e considerações morais. In: ARENDT, Hannah. A dignidade da política. Rio de Janeiro: Relume Dumarà, 1993, p. 168.

27 Idem, p. 168. 


\section{O "testemunho" de Wim Wenders}

Voltemos agora à visão do futuro de Wim Wenders, que inspirou, em parte, nossas reflexões. Em Muito além do fim do mundo, o mundo das experiências humanas é dominado, de maneira radical, pela capacidade quase ilimitada do conhecimento científico, o que resulta, entre outras conseqüências, na supressão da memória. Aí, o tempo vivenciado pelos personagens é apenas o futuro, sequer o presente. O permanente deslocamento espacial e existencial dos personagens, favorecido pela velocidade, obstaculiza qualquer enraizamento, tanto quanto o ócio.

O habitat do casal Forber é também sugestivo: não por acaso, Henry e Edith vivem entre os povos aborígines, os quais não compartilham da civilização da técnica, tampouco participam de um mundo plural, ou seja, da política, ela também, suprimida pelo poder absoluto e tirânico dos Estados Unidos, uma potência bélica que se sobrepõe a todos os demais países do planeta. Quanto ao cientista Henry Forber, embora trate com camaradagem os mbantua, não hesita em imaginá-los como suas cobaias. De resto, ganhar o prêmio Nobel, mesmo à custa de entregar a "máquina de ver os sonhos" aos norte americanos, não lhe provoca qualquer dor de consciência.

Sam vive à sombra do brilhantismo do pai, não lhe ocorre desobedecer-lhe ou enfrentá-lo, afinal, ele é o homem branco daquela tribo pós-colonial; quando o pai (ou o civilizador) se vai, ele opta por ficar entre os aborígines, no entanto solitário e agoniado. Não é o filho quem abandona o pai, mas o pai quem abandona o filho, sem permitir-lhe o usufruto de sua herança.

Edith não se atreve tampouco a entrar em conflito com os experimentos do marido, afinal, ela é também sua cobaia, assim como Claire. Apenas David, no ato mesmo de observar e registrar a história escapa ileso da loucura de um mundo sem ação, ainda que prenhe de aventuras e riscos inerentes à manipulação da natureza pelo conhecimento. E embora o mundo não se acabe mesmo depois da explosão nuclear, a técnica reina soberana sobre as circunstâncias; por vaidosa e cega, escapa-lhe o senso de que não consegue iluminar escuridão da noite, o que se pode concluir com uma lacônica afirmação de Sam: tudo o que eu quero é que minha mãe veja e que meu pai saiba que o amo. 